Portland State University

PDXScholar

7-25-1972

\title{
The effects of training at two specified intensities upon heart rate response to submaximal exercise
}

Gordon LeVerne Noraine

Portland State University

Follow this and additional works at: https://pdxscholar.library.pdx.edu/open_access_etds

Part of the Health Information Technology Commons, and the Sports Sciences Commons Let us know how access to this document benefits you.

\section{Recommended Citation}

Noraine, Gordon LeVerne, "The effects of training at two specified intensities upon heart rate response to submaximal exercise" (1972). Dissertations and Theses. Paper 1586.

https://doi.org/10.15760/etd.1585

This Thesis is brought to you for free and open access. It has been accepted for inclusion in Dissertations and Theses by an authorized administrator of PDXScholar. Please contact us if we can make this document more accessible: pdxscholar@pdx.edu. 
AN ABSTRACT OF THE THESIS OF Gordon LeVerne Noraine for the Master of Science in Teaching in Health and Physical Education presented July $25,1972$.

Title: The Effects of Training at Two Specified Intensities upon Heart Rate Response to Submaximal Exercise.

APPROVED BY MEMBERS OF THE THESIS COMMTTEE:

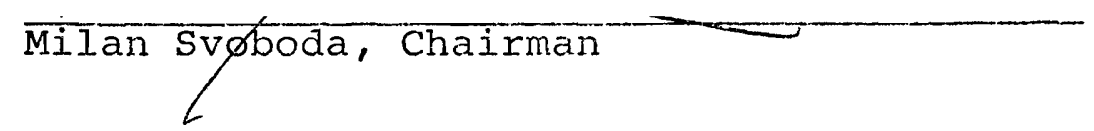

Donald Hellisor

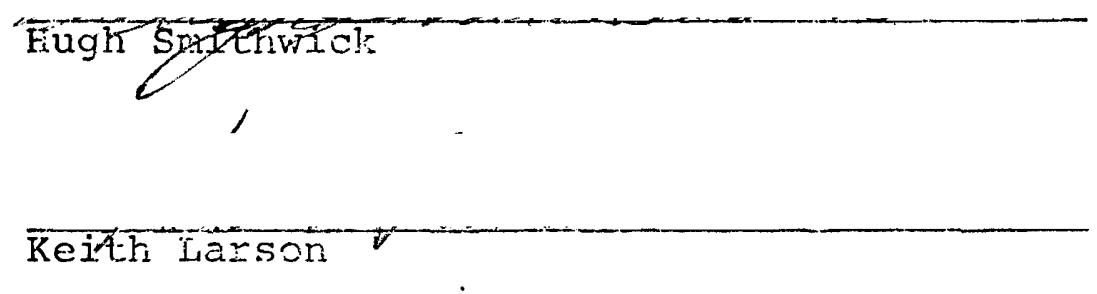

The relationship between training intensities and fitness gains was selected as a topic for analysis in this study. Forty-six college men served as subjects in one of three groups: a jogging, or moderate intensity, training group, a running, or high intensity, training group, or a control group. AlI subjects were pre- and post-tested on tre Astrand 
Bike Ergometer Work Test where workjng heart rates were measured and recorded. The two training groups participated in at least thirteen training sessions between these testing days, in which two miles were covered at the correct intensity level for each subject at each trajning session.

A review of the literature reveaied that most researchers embraced the concept of a minimal threshold of. training stimulus needed to be ret or exceeded by subjects for significant cardiovascular fitress gains to occur. Conclusions about the absolute level of this threshold varied from a low of 120 heartbeats per minuce to at least 150 heartbeats per minute, depending apparently upon the experimental evidence each researcher had gathered.

The author hypothesized that there existed a continuum of training stimuli such that training at higher intensities would produce larger heart rate decrements (a cardiovascular fitness index) than at moderate training intensities, but that noderate intensities would also produce significant gains. Furthermore, wide variations in heart rate decrements were expected to be observed within any one group, possibly inäicating differerces in initial fitresses of subjects.

The factual results of the study were:

Both experimental groups and the control group exhibited significant decrements in heart rates from pre-test to post-iest although the experimentai groups' gains were 
significant at a higher confidence level. Explanations were posited.about the possible factors which might have unpredictably caused the control group to have shown significant improvernent.

The moderate intensity training group exhibited a larger: decrement in heart rate than the high intensity training group, although the difference was not statistically significant.

There, indeed, was a wide variation of heart rate responses among individuals within any one group, possible indicating initial fitness differences.

In light of the results derived frorn this study, the author can only conclude:

Significant decreases in submaximal workload heart rates may be expected to be observed in American college men after training at moderate to high intensity levels (150 beats per minute or higher) for relatively short training periods (two days per week for eight weeks).

Large fluctuations in fitness responses among subjects withir ary one training group can be expected, due probabiy to individual differences in initial fitnesses.

ihe task of training large numbers of subjects at specified intensjty levels within a fairly realistic physical educetion setting seems to have been a fruitful approach. 
THE EFFECTS OF TRAINING AT TWO SPECIFIED

INTENSITIES UPON HEART RATE RESPONSE

TO SUBMAXIMAL EXERCISE

by

GORDON LEVERNE NORAINE

A thesis submitted in partial fulfillment of the requirements for the degree of

MASTER OF SCIENCE IN TEACHING

in

HEAITH AND PHYSICAL EDUCATION

Portland State University

- 1972 
TO THE OFFICE OF GRADUATE STUDIES AND RESEARCH:

The members of the committee approve the thesis of Gordon LeVerne Noraine- presented July 25, 1972 .

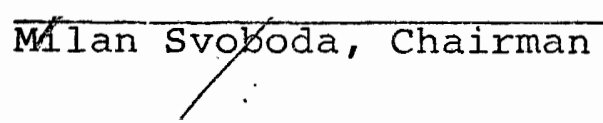

Donald Hellison

Hugir Smithíl ick

Keith'Larson'

APPROVED :

$\Rightarrow$

Lee V. Ragsdale, Head, VDepartment of Health and Physical Education $\rightarrow$

David T: Clark, Dean of Graduate Studies and Research

Juiy 28,1972 


\section{ACKNOWLEDGEMENTS}

My appreciation is expressed to my co-advisors, Milan Svoboda and Don Hellison, whose doors were always open when I needed help with any stage of this project, to Dr. Lee Ragsdale for his useful advice in writing this paper, and to my wife patty for her patience in typing this manuscript. My thanks also are extended to the subjects in this siudy, most of whom did not know what they were getting into when they registered for P.E. 190 Physical. Fitness. 
TABLE OF CONTENTS

PAGE

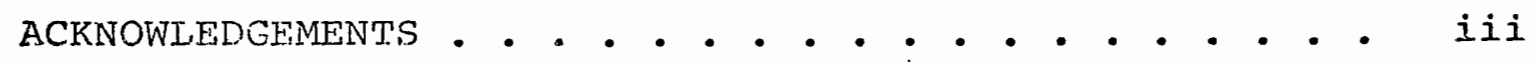

IIST OF TABIES • • • • • • • • • • • • • • • • • • • v v

CHAPTER

I INTRODUCTION. • • • • • • • • • • • • • • •

II REVIEW OF THE LITERATURE. . . . . . . . . • . 5

II STATEMENT OF THE PROBLEM. • • • • • • • • • • . 13

IV RESEARCH DESIGN AND METHODOLOGY • • • • • • • 15

subjects. • • • • • • . . • • • • 15

Data Coliected. . . . . . . . . . . 16

Testing Procedure . . ... . . . . . 17

Experimental Design . . . . . • . . 18

Training Program. • . . . . . . . . 19

Statistics and Data Analysis. . . . . . 21

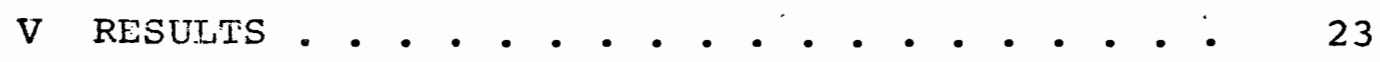

VI DISCUSSION. • • • • • • • • • • • • • • • • • 31

VII IMPLICATIONS FOR FUTURE RESEARCH. • • • • • • . 37

VTII SUMMARY AND CONCLUSIONS • • • • • • • • • • • 39

REFERENCES • • • • • • • • • • • • • • • • • • . 42

APPENDIX . • . . . . . . . . . . . . . . . . 45 


\section{IIST OF TABLES}

TABLE

PAGE

I Mean and Standard Deviations of Pre--test

Heart Rates, Post--test Heart Rates,

and Changes in Heart Rates. . . . . .

II Analysis of Variance of Initial Test Heart

Rates . . . . . . . . . . . . . .

III Paired $\dot{T}$-tests for Pre-post Heart Rate

Changes Within Groups (Onemailed Tests).

IV Analysis of Variance of Heart Rate Changes

Among the Three Groups. . . . . . .

$\mathrm{V}$ Means and Standard Deviations of Selected

Subject Variables . . . . . . . . . 


\section{CHAPTER I}

\section{INTRODUCTION}

Many physiologists and physical educators have expiored the relationship between physical training programs and improvements in cardiovascular or aerobic "fitness" parameters. A workable definition of cardiovascular fitness for use in this paper is the ability of the circulatory and oxygen transport systems to allow one to perform sustained muscular work at moderate to heavy workloads.

Physiologists are specifically most interested in precisely determining the nature and extent of physiological changes within the circulatory and oxygen transport systems caused by identifiable training stimuli. This information allows physiologists and exercise physiologists within the field of physical education to gradually expand the knowledge content of their own farticular disciplines.

other physical educators may be more interested in using such information for more applied purposes such as designing physical education programs to meet desired objectives (e.g. cross-country running or physical fitness units for improving cardiovascular fitness). Coaches, who work in a special type of physical education program, may also be desirous of using information about the relationship between training and cardiovascular endurance gains in 
designing their own farticular training or practice programs in athletics.

Doctors are also increasingly using such information to steer heart-attack patients into rehabilitative physical fitness programs where patients' general cardiovascular and caraiac functionings may be significantly improved. They also might use such information to advocate "preventative maintenance" to their patients.

Much of the general public seems also to be interested in the training/fitness relationship, as evidenced by the sale of books such as Cooper's Aerobics and by the increase of joggers sighted daily.

Not to belabor a point, the nature of the relation-ship between physical training and cardiovascular endurance parameters is of interest to increasing numbers of the population. It, therefore, seems to be of sufficient importance to be investigated thoroughly and systematically.

The author has looked at considerable research dealing with the relationships between selected training variables and cardiorespiratory fitness gains as measured by maximal oxygen uptake changes. In selected studies, researchers have found significant increases in maximal oxygen uptake due to training varying from 1 percent to 35 percent $(1,2,3,4,5,6$, $7,8,9,10,11,12,13,14,15,16,17,18)$. Each research design, however, was somewhat unique as each researcher appeared to take a little different approach to the problem of studying training effects. Some focused on the effects of age or 
initial fitness upon fitness changes, while others were more concerned with the effects of frequency, duration, intensity. or nature of training program. Ali of these variables seemed to have some effect on the influence of training on maximal oxygen uptake.

The way in which each variable specifically affects training has only been very crudely examined. The difficulty in determining precisely the specific effects of training variables on fi.tness parameters lies in attempting to isolate and study one variable at a time while holding all other significant variables constant. The author feels this has been done well in very few studies. However, in looking at the mass of unique training studies, it is increasingly apparent that some training variables are more important than others. It is becoming evident that initial fitness of subjects and intensity of training stimuli are two such crucial variables, as shephard and Sharkey have stated $(19,20)$.

Unfortunately these variables have often been overlooked or not controlled in previous training studies. In describing their training regimes, many researchers have referred to a jogging or a running program, a middle- or long-distance running program, a celisthenic or circuit-training program, or some other designation of program. let it would be purely corjectural to estimate hui strenuous these training workloads were in objective intensity measures such as how much they taxed each individual's maximal aerobic capacity or what the 
average level of heart rate achieved during work was.

Thus the author chose to study specifically the effect of intensity of training upon cardiovascular fitness change (as measured by a change in heart rate on a standardized submaximal work test). Working heart rate was used as a measure of the intensity of training. In light of the scope of this study, only literature which focused on training intensity was reviewed. In fact, due to the lack of agreement about subjective estimates of work intensity, only studies using heart rate as a measure of training intensity were examined. 
CHAPTER II

REVIEW OF THE LITERATURE

There does not exist an abundance of studies using heart rate as a measure of training intensity. Fet there are a few such studies and some of these may provide some meaningful information and insights.

Sharkey has done at least tro studies using heart rate. as a measure of training intensity. In one study (2I), he divided sixteen college men (eighteen to nineteen years old) into one of four groups, three experinental groups and one control group, each consisting of four subjects. The three experimental groups were trained on a treadmill for six weeks: three days per week, approximately ter minutes daily, at one of the following intensity levels: 120 heartbeats per minute, 150 heartbeats per minute, or 180 heartbeats per minute. The control group did not participate in any training program. A treadmill running at the rate of 3.5 miles per hour at varying grades was used to produce the desixed training heart rates. Al1 sixteen subjects were pre- and post-tested on both the Astrand-Rhyming Step Test and the Balke Treadmill Test. The two tests correlated highly $(r:=.81)$ on the pre-test data. As measured on the Balke Test, both the 180 heart rate group and the 150 heart rate group were significantly different from the other two groups in improvement in work time on the 
treadmili. As measured on the step test, only the 180 heart rate group was significantly different írom all other groups in predicted maximal oxygen uptake. Sharkey nade these two concluding statements: (1) researchers should be wary of predictive results from the step test, and (2) perhaps 150 heartbeats per minute may represent a threshold training stimulus. Sharkey (19) used a different research design to test for intensity/auration jrteraction effects upoin training results. He used thirty-six college-age men, six in each of six experimental groups. The design was a three by two factorial where groups trained at one of three intensities (130, 150, or 170 heartbeats per minute) at either of two durations ( 7500 or 15000 kilo-pound meters total work done). Training took place for 7.5 to 30 minutes daily, three times per week, for six weeks on a bicycle ergometer. Pre-- and post-testing was done using three different measuring devices: (1) the Astrand-Rhyming Step Test, (2) the Balke Treadmill Heartrate 170 Test, and (3) the Physical Work Capacity Heart Rate 170 Test on the bicycle ergometer. All of these tests were usea to determine or predict maximal oxygen uptake. linese pre-tests resulted in fairly low intercorrelations $(x=.42$ to .48$)$. There were no statistically significant differences noted between any of the groups. However, evidence did seem to show that training intensity was a more crucial variabie than duration and that the effect of initial fitness upor changes in fitness was considerable $(r=-.539$ between initial fitness and increase in fitness). 
Shephard (20), in a commentary upon Roskamm's paper (22) delivered at a 1967 Heart and Fitness Convention in Canada, made similar statements. He used a multiple regression arialysis to study various fitress parameters in unfit inen. He condluded that of ali these parameters, only the following two variables significantly influenced the response to training: (1) initiai fitness of subjects, and (2) intensity of training. His conclusions are based on his study of twenty-five low-fit men (mean maximal oxygen uptake of 35.6 milliliters per kjlogram body weight per minute) who trained at either 35 percent, 65 percent, or 90 percent of their aerobic capacities. All three groups showed some inprovernent in maximal oxygen uptake due to training. He concluaed that a heart rate of 120 (representing 35 percent of aerobjc capacity in some subjects) may exert a training effect on very low-fit sedentary men.

Yeager and Brynteson (23) studied eighteen college-age females, training three days per week for six weeks at a heart race of 144 beats per minute. Three experimental groups were studied; groups trained on a bicycle exgometer for either ten, twenty, or thirty minutes daily. All girls were pre- and post-tested on the Astrand Bike Ergometer Test usad for predicting maximal oxygen uptake and a Physical Work Cayacity progressive bike test. Ar analysis of variance shoved no significant differences between groups but the thirty minute group significantly improved on both tests while the other two groups significantiy jmproved on either one test or 
the other but not both. Hence 144 hearibeats per minite was adequate as a trainirg stimulus for these subjects.

Gemill, Booth, ara Pocock (24) studied three male subm jects who rode bicycle ergometers one-half hour dajjy, five days per week, for four weeks. Fiacin pedalied at his own constant workload. The initial heart rates of the thres subjects after thirty minutes of pedaliing curing bhe first few days of training was between 135 and 150 beats per ninute. These heart rates decreased greatly in al. three men after training to about 115 io 125 beats per minute. Ever though this study aid not deal statistically with these results and did not hold training intensity constant, it seems noteworthy that trajning did take place at this modexate and decreasing intensity level. It should be noted that training and testing were both done on the same instrument--the bicycle ergometex. This procedure probably incxeased the probability of noticrable changes in cardiorespiratory fitness parameters. Karvonen, Kentala, and Mustala (25) studied six male medical. students (ages twenty to twenty-three) who trained on a treadnill thirty minutes daily, four or five days per week, for four weeks. These subjects trained at individual heart rates which varied from 135 beats per ininute to 180 beats per minute. The experimenters roticed that subjects training at a heart rate above 150 beats per minute had to have their workloads incyersed somewhat as the training sessions progressed. thos exhibiting increased cardiovason? ar efticiency. That is to say, wher more work can be dore with the same level of 
heart rate, one is considerea more efficjent. The men training below 150 beats per minute did not demonstrate this effect to tine same exterit.

The experimenters also locked at training heart rate as a percentage of the difference between maximal heart rate and resting heart rate for the six subjects. They then concluded that perhaps there is a "cut-off" point or threshold training level existing between sixty and seventy percent of this difference in heart rates, below which no significant training can occur and above which significant results can be expected.

Roskamm (22) used the same procedure, i.e. taking a percentage of the differerce between maximal heart rate and resting heart rate, as a metnod of determining training stimuli for various experimentaj groups. He used eighty soldiersubjects, twenty in each of four groups--truge experimental groups and one cortrol group. Experimental groups trained on a bicycle ergometer for one-half hour daily, five days per week, for four weeks. Group I subjects workea at a constant workload at seventy percent of the aifference between their own maximal heart rates and their resting heart rates. Group Ir subjects worked for one minute ats a workload fifty percent heavier than that of Group I, and then worked for one minute at a workload fifty percent lighter than that of Group I. This patiern was alternated every minute for the fuil thirty minutes. Group III subjects workeả for two and onewhalf minutes at a workload fifty percent heavier than Group I and 
then for two and onemhalf minutes at a workload fifty percent lighter than that of Grovp I, also for a total of thirty minutes. Group IV served as a control group. Thus all three experimental groups did the same amount of work, although in different ways.

All three groups exhibited signisicant gains over the control grolip ( $<.001$ ). Gains were masured in the following two ways: (1) ability to do more work after training at the same pre-test heartrate, and (2) ability to do the same amount of work with a lower heartrate. The author's conclusion is that training at a steady workload (Croup I) may be best for reducing heart rate at any given submaximal workload, but that interval training methods (Groups II and III) serve as better preparation for maximal work.

Two other studies have been done using heart rate as a measure of training intensity but in a little different way. Faria (26) and Brooker (27) had subjects train until their heart rates reached designoted levels rather than training subjects at specified heart rates for a period of time. Hence their results might not be directly comparable to other studies cited, yet they may have some bearing on this discussion of the training intensity/fitness relationship.

Faria (26) divided forty male subjecis (mean age 20.5 years) equally into one of four groups--three experimental groups and one control group. The three experimental groups worked from fifteen to twenty-five mimltes per day, five days ver week, for four weeks on a 17.5 inch high bench, stepping 
up thirty times per minute until specified heart rates were reached. Group I worked until subjects' heart rates rose to betiven 120 ana 130 beais per minute. Group II worked until heart rates rose betweer 140 and 150 beaẗs per minute. Group III worked urtil heart rates climbed between 160 and 3.70 bea's per minute. Group IV served as a control.

All four groups were tested on a bicycle ergometer Physical Work Capacity Heart Rate 180 test. In this test, a subject rode the bicycle ergometer (at a constant speed) until his heart rate reached 180 beats per minute. The beginning workload was quite light, but the working resistance was increased one kilo-pouna every five minutes. Pre-test and post-test measurements of total work done were recorded for all subjects. All three groups exhibited a training effect. The 140 to 150 and the 160 to 170 heart rate training groups demonstrated significantly greater increases in total work done than the control group $(p<.05)$. The 120 to 130 heart rate group was not observed to be significantly different than the contrcl group. Faria concluded that a threshold level of training intensity may exist somewhere below 140 heartbeats per minute.

Brooker (27), using eighteen male subjects divided among tinree experimental groups and one control group, found that training five times per week for six weeks on a bicycle ergometer at interisities of up to 150 or 180 heartbeats per mimute significantly decreased heart rate during work and recovery as measured on the same work test administered pre- 
and post-training. The controj group and the 120 heart rate group dia not exhibit a: significant change in this training variable.

In summary, most of the researchers cited tend to embrace the concept that a threshold level stimulus must be met or exceeded for significant cardiovascular training to occur. However, the level of this threshold stimulus seems to be very much in doubt, evidence being cited to support thresholds from as low as 120 beats per minute to as high as 150 beats per minute or more. 
CHAPTER III

STATEMENT OF THE PROBLEM

This stuayy was directed toward clarifying a somewhat confusing picture. Studies have shown that training at varicus intensities of from 120 heartbeats per minute to 180 heastbeats per minute or more can cause significant gains in cardiorespiratory fitness in a variety of subjects. Several authors have suggested that there might be some sort of training intensity threshold level which a person must train at or above in order to achieve a significant training effect. The nature of this threshold is not agreed upon as different researchers have provided evidence for different thresholds of training stimuli. The required threshold seems to depend somewhat upon the prevajiling conditions of the particular experiment.

Most experimental research in this area has been done using small numbers of subjects training in a laboratory setting-using a treadmil, bycycle ergoneter, or step test. This perticulor experiment attempted to look at intensity of training effects by using a large number os subjects in a more naturai physicai education setting--running and jogying out-of-doors in a pinsical fitness ciass.

The author hypotinsized that there exists no one training threshold but that there is a contiruum of trairing 
stimuli. Eurthermore it was hypothesized that the response to such stimuli depends both upon the intensity of the stimuli and the initial fitness of the subject. The ramifications of this hypothesis are two-fold: (1) at any given training intensity, some subjects will exhibit significant fitness gains while others may show no gains at all, and (2) with ranciom distrjbution of subjects and subject fitnesses, a highex training intensity will produce greater average gains than a more noderate training intensity.

specifically, it was hypothesized that: (1) training at the higher intensity level would produce a larger and significant hoart rate decrement while training at the lower intensity wovld produce a smaller but still significant training effect, and (2) wide differences in heart rate changes woula be seen among subjects within any one group, due perhaps to initial fitness differences. 
CHAPTER IV

RESEARCH DESIGN AND METHODOLOGY

\section{SUBJECTS}

Forty-six male students (mean age 22.2 years) volunteexed from three physical fitness classes taught by the auchor at Fortland State University to serve as subjects in one of two experimental groups. All members of the three physical fitness classes were informed about the nature of the study to be undertaken. They were informed that they were to be involved in a training study and that activities which might facilitate training, such as swimming, cycling, running, etc., done outside of class were not to be allowed. Those students who could not accept this agreement were dropped from the study although most of them still participated in the class. Thus of seventy initial potential subjects, forty-six volunteered to restrict outside activities which might have distorted the significance of measured fitness changes.

These forty-six subjects were randomly assigned to one of two experimental groups. Group I, hereafter referred to as the jogging group, consisted of twenty-three subjects who trained at an intensity level between 140 and 160 heartbeats per minute. Group II, hereafter referred to as the running group, also consisted of twenty-three subjects who trajned at 
an intensity level between 170 and 190 heartbeats per minute. In each of the three physical fitness classes were approximately equal numbers of "joggers" and "runners".

Sixteen male archery students (mean age 22.8 years) vol-unteered to serve as a control group, agreeing to the same outside-of-class physical activity restrictions as did the experimental groups. Thus it seemed reasonable that they would serve as an adequate control group, since physical training activities had been sufficiently restricted for them.

\section{DATA COLLECTED}

All subjects were initially tested for working heart rates while performing the Astrand bicycle ergometer six minute work test as described by Astrand (29, pp.15-18). Trijis test was chosen for a number of reasons. It is easy to administer and it is objective. Testing procedures are descirbed clearly in several sources (2, pp.617-623, 29, pp.15-18). It is a valid test to the extent that a change in working heart rate has been accepted by physiologists and physical educators as a fairly accurate index of cardiovascular fitness change when viewed in a pre-test to post-test situation. $(2, p .617)$. Preparations are not yet adequate at the Portland State University exercise physiology laboratory to directiy measure maximal oxygen uptake, which is generally accepted as the best single measure of cardiorespiratory fitness. Hence a change in heart rate, measured as the difference between pre-training heart rate and post-training heart rate, was selected to be the index of cardiovascular fitness change in 
this study.

Other data were gathered which were likely to have some bearing on the interpretation of results. Subjects' ages and weights were recorded. Rjso each individual who was posttested filled out an ectivity questionnaire to serve as a double-check on his activities during the quarter as well as a matter of interest and speculation to the researcher.

\section{TEETING PROCEIUUR}

The mork test used in this study consisted of a six minute bicycie ergometer (Morark style) ride performed at a constart workload and at a constant pedalling rate, in this case fifty revolutions per: mirute. A metronome was used to insure a constant rate for all subjects. This metronome was set $3 t$ a rate of 1.00 beats per minute, each beat coinciding with one-half revolution or "step" on the bicycle ergometer.

Each subject tested was given sufficient opportunity to familiarize himself with the pedalling rate by practicjas this with the bike in the free-wheeling positon until precision was obtained. A workload was then selected by joint effort of the researcher and subject which was estimated to bring the subject's heart rate up to between 130 and 170 beats per minute for the last two minutes of work. This method of workicaa aetermination was chosen because it was fejt that potentiai heart rate changes to be observed could be significantiy affected by the level of initial heart rate. Heart rates between 130 and 170 beats per minute were arbitrarily 
approved as lying within an acceptable range of initial test heart rates. Those subjects who fajled to meet this criterion were later retested at a "proper" workload. Testing worklcads used were at either $450,600,750$, or 900 kilo-pond meters per minute. Each subject was pre- and post-tested at the same workload, thus making both of his heart rate responses directly coinparable.

Heart rate was measured by the researcher (or assistant) holding a stethescope over the heart on the front of the subject's chest. Heart rate was taken for the last thirty seconds of both the fifth and sixth minutes of work. The testing heart rate recorded was the average of the two heart rates measured. The height of the bicycle ergoneter seat was adjusted in each case to provide maximum pedalling ef-ficiency and comfort for each subject. Generally this meant. a height which allowed for nearly complete extension of the downward leg at the bottom of the pedalling cycle.

\section{EXPERIMENTAL DESIGN}

All subjects were pre-tested during the first week of spring quarter. Both experimental groups engaged in a training program from week two to week nine--an eight week trairing session. The control group participated in one of two archery dasses, two days per week, for the intervening eight weeks. In the tenth week of the quarter, all subjects remaining in the study were post-tested on the same work test used for pre-testing. Although an extended discusston will 
follow, it is significant to mention here that nine of sixteen control sukjects did not returr for retesting, seven of twenty-three runing subjects were dropped from the study for various reasons, but none of the twenty-three jogging subjects dropped out of the training or testing programs. Thus sixtytwo subjects were pre-tested, but only forty-six of these were post-tested and hence ali data referred to in this study was compiled from the remaining forty-six subjects.

\section{TIRAINING PROGRAM}

The three physicai fitness classes met at one of the following times, each for two days per week for one hour: (1) 9:00 A.M. Mondays and ìednesdays, (2) 8:00 A.M. Tuesảays and Thursdays, or (3) 9:00 A.M. Tuesdays and Thursdays. There were a total of sixteen possible training sessions (two times per week for eight weeks). Each session lasted from thirteen to thirty minutes depending on each subject's speed of performance.

With the exception of one rainy day spent training in the gymnasjum, all running, jogging, and walking was done on the roof of the portland State University physical education building, circling counterclockwise around the fenced-in tennis courts. The "track" there is approxinately 215 yaras in circumference. Each day of training each experimental subject in attendance moved at his particular pace around this track seventeen times, a total distance of approximately two miles. All subjects stopped briefly after the third, sixth, ninth, 
twelfth, fifteenth, and seventeenth (last) laps to take a ten second carotid artery pulse count and record this on a three-by-five note card which they carried with thern when they rar. Subjects had ample time to become proricient at measuring their own heart rates before training actually began. This technique is considered a very reliable nethod of determining heart rate when trained subjects are used (28).

Although it would have been desirable to measure heart rates during work, this was not technically possible. Thus immediate post-exercise heart rates were used to determine the intensity level of training. This does not yield a perfectly accurate picture of working heart rates during exercise due to individual differences in immediate recovery patterns. For the purposes of this experiment, however, the technique followed was acceptable since heart rate was taken immediately after stopping and for only a ten second period.

Jogging group subjecis were instructed to walk, run, or jog arourd the track at a rate which would bring up and keep their heart rates between twenty-three and twenty-six beats per ten seconds (138 to 156 beats per minute). Running group subjects were instructed to run at a pace which would keep their heart rates between twenty-nine and thirty-two beats per ten seconais (174 to 192 beats per minute). There was a large clook near the track where most subjects would fairly suddenly stop: check their pulses, record them, and begin runing again. Other subjedts used their own watches for the same purpose. When a subject peiformed at an ircorrect pace, he adjusted it 
as necessary to produce the desired heart rate. As the training sessions progressed, fewer and fewer adjustnients were necessary and more correct heart rate responses viere this made. Each time a subject performed at an incorrect pace, this was noted and recorded. Fighteen or less such mistakes were permissible for subjects to remain in the study. since there were six heart. rates recorded daily, one absence counted for six mistakes. In effect then, subjects had to complete at least thirteen correct training sessions out of a possible sixteen.

\section{STATISTICS AND DATA ANAISYSIS}

The following data was gathered for each experimental subject:

1. Initial test heart rate.

2. Final test heart rate.

3. Change in heart rate (from initial test to final test).

4. Age in years.

5. Weight in pounds when initially tested.

6. Testing workload.

7. Activity questionnaire.

8. Total percentage of correct training performances.

9. Mean training heart rate.

Data on items one through seven were also recorded for ail control subjects.

Several statistical procedures were used to examine relationships between training intensity and cardiovascular fitness improvement as measured by heart rate changes. An analysis of variance of pre-test heart rates was computed to check 
for significant initial group differences which might have affected an interpretation of results. Possibly a group with a significantly higher inicial test heart rate would have a different potential for change due to training than one with a lower initial heart rate. Each group was also separately analyzed to check for significant pre-test to post-test rate changes. Paired t-tests were used here. Finally, an analysis of variance was computed to check for significant dif-ferences in heart rate changes among the groups.

Means and standard deviations for each group were computed as applicable for subjects' ages, weights, testing workloads, attendance records, and training heartrates. Other data, such as training time and activity questionnaires, were analyzed in a non-statistical and more subjective and interpretive manner. 


\section{CHAPIER V}

\section{RESULTS}

Table I contains data on mean pre-test and post-test heart rates as well as mean heart rate changes for the three groups undex study. It can be seen from the tabie that iritial test heart rates for the three groups are roughly equivalent (means range from 151.7 to 1.56 .9 beats per minute). An anal-ysis of varianoe (Table II) of premtest heart rates was conputed to check for jnitial significant aifferences in heart rates of members fron each of the three groups. An Foratio of 0.82 was determined from such an analysis which was not statisticaliy significant at an acceptable confidence level $(F=5.18$ and 3.23 needed for significance at the .01 and .05 levels of confidence respectively).

Thas there were no significant differences in initial heart: rates among the groups. This homogeneity was desirabie as the aythor has speculated that changes in heart rates might be affected by the level of initial heart rates. Hence a group with a significanty higher prewtraining heart rate right have a different potential for change than a group with a Jowox pre-test heart rate. This possibjlity might make resuts more aifficult to interpret accurately.

Paired totests (Table III) were computed within all three groups to chesk fox significart changes in heart rates from 
TABIEE I

MEANS AND STANDARD DEVIATIONS OF PRE-TEST HEART RATES, POST-TEST HEARI RATES, AND CHANGES IN HEART RATES

\section{CONTROL GROUP $(N=7)$}

MEAN S.D.

Initial. Test Heart Rate

(beats per minute) $\quad 152.40 \quad 16.50$

Final Test Heart Rate

$\begin{array}{lll}\text { (beats pex minute) } & 147.70 & 15.90\end{array}$

Charge in Heart Rate

(beats per minute)

$4.70 \quad 4.70$

JOGGING GROUP $(\mathrm{N}=2.3)$

MEAN S.D.

Initial Test Heart Rate

(beats per minute)

$151.70 \quad 10.82$

Final Test Heart Rate

(beats per minute)

136.70

13.17

Change in Heart Rate

(beats per minute)

$15.00 * 12.07$

RUINNING GROUP $(\mathrm{N}=\mathrm{I}, 6)$

MEAN S.D.

Initial. Test Heari kate

(beats per minute)

156.90

12.45

Final Test Heart Rate

(beats per minute)

144.77

10.08

Change in Heart Rate

(beats per minute)

12.13

9.60 
TABIJE II

ANALYSIS OF VARIANCE OF INITIAL TEST HEART RATES

\begin{tabular}{lcccc} 
Variance Source & df & Mean Square & F & $(p<.05)$ \\
Total & 45 & 154.7 & & \\
Between group & 2 & 132.0 & .82 & 3.23 \\
Within group & 43 & 155.7 & & \\
\hline
\end{tabular}


TZABLE III

PAIRED T-TESTS FOR PRE-POST HEART RATE CHANGES

WITHIN GROUPS (ONE-TAILED TESTS)

CONTROL GROUP

$t$-ratio $=2.31(p<.05) \quad t=1.943$ needed for significance at the .05 level.

$t=3.143$ needed for significance at the .01 level.

$t=5.959$ needed for significance at the .001 level.

JOGGING GROUP

$t=1.717$ needed for significance at the .05 level.

$t=2.508$ needed for significance at the .0I level.

t-ratio $=6.00(p<.001) \quad t=3.792$ needed for significance at the .001 level.

RUNNING GROUP

$$
\begin{aligned}
t= & 1.753 \text { needed for significance } \\
& \text { at the } .05 \text { level. } \\
t= & 2.602 \text { rieeded for significance } \\
& \text { at the .0l level. } \\
t= & 4.073 \text { needed for significance } \\
& \text { at the .00I level. }
\end{aligned}
$$

t-ratio $=5.05(\mathrm{p}<.001) \quad t=4.073$ needed for significance 
the pre-test to the post-test. All three groups, the control group included, exhibited significantly lower heart rates on the post-test. The mean decrease in heart rate for the jogging group was 15.00 beats per minute (t-ratio $=6.0, p<.001$ ). Mean decrease in heart rate for the running group was 12.10 beats per minute $(t$-ratio $=5.05, p<.001)$. Mean decrease in heart rate for the control group was 4.72 beats per minute $(t$-ratio $=2.31, p<.05)$. One-tailed tests for significance were used here. Although all three groups exhibited significantly lower post-test heart rates, the mean heart rate changes of the two experimental groups are significant at a higher confidence level than the mean heart rate change of the control group.

An analysis of variance (Table IV) was then computed to check for significant differences among groups of the above changes in heart rates. This analysis produced an F-ratio of. 2.58 (an F-ratio of at least 3.23 being needed for significance at the .05 level). Thus there were no statistically significant group effects due to training in this experiment. Neither experimental group improved significantly more than the other or more than the control group. There was a great range of heart rate changes noted among indivjdials within any one group (see Appendix). Standard deviations were calculated for heart rate changes among members of each group studied. It was observed that all three groups exhibited relatively large standard deviations from their respective nean changes in heart rate values. 
TABIE IV

ANAJYYSIS OF VARIANCE OF HEART RATE CHANGES

AMONG THE THREE GROUES

\begin{tabular}{lcccc}
\hline Variance Source & df & Mean Square & F & F \\
\hline Total & 45 & 118.7 & & \\
Between group & 2 & 285.5 & 2.58 & 3.23 \\
Within group & 43 & 110.7 & & \\
\end{tabular}


This might very well reflect differences in initial fitnesses of subjects, which in turn might partially determine how much effect a given intensity of training had on each subject.

Other data about the subjects in the study are included in Pable $V$. It is observed that the jogging group trajned at a mean intensity of 151.2 heartbeats per mirute, while the running group trained at a mean intensity of 183.5 heartbeats per minute. Means and standard deviations for age, weight, and testing workload were computed and interpreted. None of the three groups appeared to have differed significantly in any one of these three variables. Not only are the group means for any given variable fairly close, but the standard deviations from the means are relatively large, suggesting that it would not be found that there were significant differences among the groups in age, weight, and testing work1oad. The two experimental groups did not differ noticeably in ciass attendance (92.I percent of perfect attendance for the running group Vs. 92.7 percent of perfect attendance for the jogging group). Although accurate data was not recorded for this variable, the author observed a decrease in work time for both experimental groups as training sessions progressea. Thus the same work intensity (as measured by heart rate) was gradually performed more rapidly by nost subjects as the training sessions progressed. 
TABLE V

MEANS AND STANDARD DEVIATIONS OF SEJACTED SUBJECT VARIABLES

MEAN

S.D.

AGE (in years)

Control Group

23.14

3.68

Jogging Group

22.57

3.83

Running Group

21.31

2.80

WEIGHT (in pounas)

Control Group

170.00

21.90

Jogging Group

170.83

21.68

Running Group

164.81

21.64

WORKLOAD (in k.p.in.)

Control Group

2.57

0.41

Jogging Group

2. 41

0.39

Running Group

2.40

0.40

ATTENDANCE (percentage of possible)

Jogging Group

92.75

4.80

Running Groun

92.05

5.73

HEAPI RATE TPATNING INTENSITY

(beats per minute)

Jogging Group

151.20

2.54

Funning Group

183.54

2.40 
CHAPTER VI

DISCUSSION

Several of the results are quite surprising at first glance and seem to contradict previous evidence and to reject the experimental hypothesis. It is difficult to interpret: the following results:

1. The control group improved significantly $(\mathrm{p}<.05)$.

2. No significant differences between groups in heart rate decrements were observed.

3. The jogging group improved slightly more than the running group.

The size and nature of the control group may well have had a detrimental effect upon meaningful statistical analysis of the results of this experiment. The control group dwindled from sixteen subjects to only seven subjects from pre-test to post-test. One wonders what selection factors (j.f any) may have been involved in those volunteering for post-testing. Were they, perhaps, a more physically active grolp than those who did not take the post-test? If this were true, might this not have destroyed the randomness of the cortrol group, a quality which is assurned to be present when statistical procedures of this nature are computed. Did the control group, in fact, maintain the same activity pattern between pre- and post-testing as they had before pre-testing? The activity questjonrajre, unfortunateiy, did not help answer this particular question. Tt provided information relating 
only to activity patterns during the period between pre- and post-testing. Thus it is unknown if activity patterrs before the pre-test were changed during the space of time between the two tests. In any event then, it is imposisible to separate these possible extraneous effects from legitimate influences upon a control group.

The control group was designed to be used for two purposes: (1) to check for a possible laaning effect from one testing period to the next, and (2) to evaiuate a possible general seasonal effect upon college subject populations. Thus under ideal conditions, a control group would have helped to determine the unique effects of a training regime upon experimental groups by serving as a yardstick of comparison. However, it is wondered if the control group here has served its purpose or if it has served only to confuse the issues. This is, indeed, a difficult question to answer.

Perhaps the above consideration of the limitations of the control group may partially help answer another question-why there were no statisticaliy significant differences among groups in heart rate changes. Since all three groups improved signifjcantly, including the control group, it is less likely for signiricant differences between groups to be observed than in a situation where the experimental groups change significantly and the cortrol group does not. Another factor, the wide spread in the amounts of heart rate change (as evidenced by the relatively large standard deviations from mean heart rate changes) reduces the probability of firding statistically 
significant differences among groups.

Finally, it is asked, despite the aforementioned problems, why there was a larger improvement in the low intersity group than in the high intensity training group. This, indeed, is a key issue if it is argued that there exists a continuum of training responses facilitated by different training intensity levels. There are several possible explanations for the results observed here.

One possibility is that these results occurred by chance. In fact, the analysjs of variance among the ihree groups signifies that these results might not reoccur in a subsequent duplicated experiment. However, there may be another reason why there is some noticeable difference between the two experimental groups.

Both of the training groups were composed initially of twenty-three subjects. Seven subjects from the running group either aropped out voluntarily, became injured, or did not othervise meet the performance criteria for acceptance as valid subjects. No subjects were eliminated from the jogging group, however. Thus it appears that some force or forces made it more difficult for running group slibjects to meet the criteria for acceptance as subjects than for jogging group subjects. It is hypothesized here that trairing at the higher intensity level (mean heart rate trainea at $=183.5$ beats per minute) is significantiy more psychologically and/or physically stressiui than training at a more moderate intensity level (mean heart rate trained at $=151.4$ beats per minute). 
As evidence for this conjecture, the author submits the following individual reasons for subject withdrawal from the study. Three subjects suffered leg or ankle injuries and had to withdraw from the study. Two subjects were unable to maintain their heart rates at a high enough level to meet the criteria for subject acceptance. Two other subjects failed to meet the attenaance requirements of the class (perhaps to avoid the strain of training at such an intense 1eve1).

The effect of this insidious selection process upon the mean heart rate change for the running group is unknown and unpredictable. The absence of the seven running group subjects who aropped out of the study might have changed the potential mean heart rate decrease for the running group and thus artificially distorted the results actually observed to some degree.

I'here are two other possibilities which are considered in attempting to interpret differences between jogging and running group improvements. The first of these possibilities is that perhaps there is, indeed, a threshold level of training intensity above which significant training will occur and below which none will occur. Thus if, in this group of subjects, the threshold of training intensity were 135 beats per minute, both experimental. groups mighi have been expected to show similar gains since both trained above the critical level. In this threshold model it would be hypothesized that the relative intensity of training is not crucial as long as the absolute threshold training stimulus is surpassed. 
However, the author feels that this threshold model is not verified or strengthened by the existing experimental evidence. There is considerable disagreement about the absolute level of such a possible threshold (from 115 to 150 heartbeats per minute or more), thus jndicating that each person may have his own particular threshold of training stimulus. Furthermore, in studies with similar populations, higher intensity groups have shown more gains than lower intensity groups, although lower groups have shown some significant improvements in cardiovascular fitness parameters. Finaliy, the author proposes that the nature of the testing experience may be the most crucial issue at hand in resolving the question. It must be realized that the essential fitness index considered here is change in heart rate as measured on a submaximal workload test. The mean pre-testing heart rate for the jogging group (151.7 heartbeats per minute) was nearly identical with the mean training heart rate (151.2 heartbeats per minute for that group). It is conceivable that training at the same intensity level used for testing is the most efficient method of trainj.ng. This hypothesized specificity of training intensity may be analogous to accepted principles of specificity of training programs. It is generally agreed upon that the most efficient way to train for cross-country running is to do lots of crosscountry running. Perhaps it is not only that training is most effective when practicing the same activity which is to be performed later but further that practicing the same activity at 
the same intensity will even be more effective in preparation for future performances. Perhaps, then, the jogging groups' training intensity leve] is the ideal training intensity in preparation for maximal performance on the submaximal bicycle test administered in this study.

Roskamm's conclusion (22) from his training study supports the above hypothesis. He concludes that training at a steady moderate intensity is the most desirable method for increasing performance at moderate intensities, but that interval (higher intensity) training is more suited for preparation for maximal performance.

Thus if a maximal performance test such as a two mile run time or similar all-out aerobic performance had been used in this study as the criterion for cardiovascular improvement, the running group might very well have shown the largest amount of improvement. Similarly, if maximal oxygen uptake had been the criterion used for determining improvement, the higher intensity group might well have improved more. 
CHAPTER VII

\section{IMPLICATIONS FOR FUTURE RESEARCH}

Neither acceptance nor rejection of the experimental hypothesis can be advocated based on the results of this study. Since there were no significant differences among groups in fitness changes, it is impossible to make conclusive statements about the relative merits of the alternative concepts of a training intensity threshold or of a training intensity continuum of stimuli. The author sees resolving this problem as a pertinent topic for study in future research. Perhaps some direction can be given in planning future research designs to study this question.

In light of the size of the gain made by the lower intensity group (140 to 160 heartbeat group), it would seem advisable to also study subjects training at lower intensities than these, as well as subjects training ai the higher intensities. Accompanying these diverse levels in training intensities, testing methods demanding different intensities should be used for measuring fitness gains. With such a design it would be rossible to check to determine the relationships between training intensities and testing intensities as they relate to measured fitness gains. The hypothesis that training at the same intensity level used for testing will cause the largest amount of measured fitness gains (or at 
least as large as the gains observed in higher intensity training groups) could be evaluated by using such a design. Perhaps this type of study would lead to more sophisticatea and well-developed concepts of training intensity effects upon varjous subject populations than are now generally understood. 
CHAPTER VIII

\section{SUMMARY AND CONCLUSIONS}

The relationship between training intensities and Iitness gains was selected as a topic for analysis in this study. Forty-six college men served as subjects in one of three groups: a jogging, or moderate intensity, training group, a running, or high intensity, training group, or a. control group. All subjects were pre- and post-tested on the Astrand Bike Ergometer Work Test where working heart rates were measured and recorded. The two training groups participated in at least thirteen training sessions between these testing days, in which two miles were covered at the correct intensity leve]. for each subject at each training session.

A review of the literature revealed that most researchers embraced the concept of a minimal threshold of training stimulus needed to be met or exceeded by subjects for significant cardiovascular fitness gains to occur. Conclusions about the absolute level of this threshold variea from a low of 120 heartbeats per minute to at least 150 heartbeats per minute, depending apparently upon the experimental evidence each researcher had gathered.

The author hypothesized that there existeo a continuum of training stimuli such that training at higher intensities 
would produce larger heart rate decrements (a cardiovascular fitness index) than at moderate trairing intensities, but that moderate intensities would also produce significant gains. Furthermore, wide variations in heart rate decrements were expected to be observed within any one group, possibly indicatirg differences in initial fitnesses of subjects.

The factual results of the study were:

Both experimental groups and the control group exhibited significant decrements in heart rates from pre-test to post-test although the experimental groups' gains were significant at a higher confidence level. Explanations were posited about the possible factors which might have unpredictably caused the control gioup to have shown significant improvement.

The moderate intensity training group exhibited a larger decrement in heart rate than the high intensity training group, although the difference was not statistically significant.

There, indeed, was a wide variation of heart rate responses among individuals within any one group, possibly indicating initial fitness differences.

In light of the lengthy discussion of limitations of this study found in the previous chapter, the author can oniy conclude:

Significant decreases in subraximal workload heart rates may be expected to be observed in American college men after training at moderate to high intensity levels ( 1.50 beats per 
minute or higher) for relatively short training periods (two days per week for eight weeks).

Large fluctuations in fitness responses amoung subjects within any one training group can be expected, due probabiy to indiviaual differences in initial fitnesses.

The task of training large numbers of subjects at specifiea intensity levels within a fairly realistic physical education setting seems to have been a fruitful approach. 


\section{REFERENCES}

1. Anderson, K. L. "The Effect of Physical Training With and Without Cold Exposure Upon Physiological. Indices of Fitress for Work", Canadian Medical Association Journal, 96: 801-8 $\overline{03}$, 1967.

2. Astrand, P. O., and K. Rodahl. Textbook of Work Physiology, McGraw-Hill, New York, 1970 .

3. Cunnincharn, D., and I. A. Faulkner. "The Effect of Training on Aerobic and Anaerobic Metabolism During a Short Exhaustive Run", Medicine and Science in Sports, 1(2): 65-69, $\overline{1969 .}$

4. Ekblom, E., P. O. Astrand, B. Saltin, J. Stenberg, and B. Wallstrom. "Effect of Training on Circulatory Response to Exercise", Journal of Applied Physiology, 24(4): 518-528, 1968.

5. Fikblom, B. "Effect of Physical Training on Oxygen Transport System in Man", Acta Physiclogica Scandinavica, Supplement, $\overline{5-40}, \overline{1969}$.

6. Girandola, R. "Changes in Maximal. Oxygen Intake in Relation to Measures of Body Composition Resulting from Physical Trainjng", Masters Thesis, Cal. Berkeley, 1967.

7. Harson, J. B., B. S. Tabakin, M. N. Levy, and ivedde. "Iong-term Physical Training and Cardiovascular Dynamics in Midale-aged Men", Circulation, 38: 783-799, 1958 .

8. Harper, Billings, and Mathews. "Comparative Effects of Two physical Conaitioning Programs on Cardiovascular Fitness in Man", Research Quarterly, 40: 293-298; 1969 .

9. Jackson, Sharkey, and Johnston. "Cardiorespijatory Adaptions to Training at Specified Frequencies", Research Quarterly, 39(2): 295-300, 1968 .

10 Karlsscr, J., P. O. Astrand, and B. Ekblom. "Training of the Oxygen rransport System in Man", Journal of Applied Physiology, 22(5): $1061-65,1 \overline{967}$. 
11. Kasch, F., and J. Carter, "Training Patterns in Middle-aged Mer", Journal of Sports Medicine and Physical Fitness, $\overline{10(4): 225-234,1970 .}$

12. Knehr, C. A., D. B. Dill, and N. Neufield. "Training and Its Effects on Man at Rest and At Work", American Journal. of Physiology, 136: 148-156, 1942.

13. Placheta, Z., and U. Drazil. "Application of Long-term Miedical Exam Results to the Training system of Cyclists", Journal of Sports Medicine and Physical Fitness, $4: \overline{1-7,1964 .}$

14. Pollock, M., T. Cureton, and L. Greninger. "Effects of Frequency of Training on Working Capacity, Cardiovascular Function, and Body Composition of Adult Men", Medicine and Science in Sports, $1(2): 70-74,1969$.

15. Robinson, B. and P. M. Harmon. "The Effects of Training and of Gelatin upon Certain Factors which Limit Muscular Work", American Journal of Physiology, 133: 161-169, 1969.

16. Saltin, B. "Physiological Effects of Physical Conditioning", Medicine and Science in Sports, l(1): 50-56, 1969 .

17. Vrijens, J. "The Influence of Interval Circuit Exercises on Physical Fitness of Adolescents", Research Quarterly, 40: 595-599, 1969.

18. Wilmore, J., J. Royce, R. Girandola, F. Katch, and V. Katch. "Physiological Alterations Resulting From a Ten Week Program of Jogging", Medicine and Science in Sports. 2(1): 7-14, 1970 .

19. Sharkey, B. J. "Intensity and Duration of Troining and the Development of Cardiorespiratory Endurance", Medicine and Science in Sports, 2(4): 197-202, 1970 .

20. Shephard, R. J. Commentary on (22), Canadian Medical Association Journal, 96: 1000, 1967.

21. Sharkey, B. J, , and J. P. Holleman. "Cardiorespiratory Adaptations to Training at Specified Intensities", Research Quarterly, 38: 698 -704, 1967. 
22. Roskamm, H. "Optimum Patterns of Exercise for Healthy Adults", Canadian Medical Association Joujnal, 96 : 895-899, Mar. 1967.

23. Yeager, A. ard P. Brynteson. "Effects of Varying Training Periods on the Development of Cardiovascular Effeciency of College Women", Researcli Quarterly, 41: 589-592, 1970 .

24. Gemmil1, C., w. Booth, and B. Pocock. "The Physiological Effect of Daily Repetition of the Same Amount of Light Muscular Work", American Journal of Physiology, .92: 253-270, $19 \overline{30 .}$

25. Karvonen, M. J., E. Kentala, and O. Mustala. "The Effects of Training on Heart Rate", Annales Miedicinae Esperimentalis et Biologiae Fenniae, 3(3): $307-315,1957$.

26. Faria; T. E. "Caraiovascular Response to truercise as Influenced by Training of Various Intensities", Researci, Quarterly, $4 I(1): 44-50$, March, 1970 .

27. Brooker, C. "üse of Efficiency as a Measure of Endurance Training Intensity", Research Quarterly, 29(4): 865-871, 1968 .

28. Pollock, M., Brouida, and Kandricks. "Validity of Palpation Technique of Heartrate During Training", Research Quarterly, 43(1): 77-83, 1971 .

29. Astrand, P. O. Work Tests With the Bicycle Ergometer, $A B$ Cyselfabriken Monark, varberg, Sweden. 
APPENDIX

CONTROL GROUP CHARACTERISTICS

\begin{tabular}{|c|c|c|c|c|c|c|c|}
\hline $\begin{array}{l}\text { Subject } \\
\text { (Initials) }\end{array}$ & & $\begin{array}{l}\text { Initial H.R. } \\
(\text { b.p.m.) }\end{array}$ & $\begin{array}{l}\text { Final H.R. } \\
(\mathrm{b} \cdot \mathrm{p} \cdot \mathrm{m} .)\end{array}$ & $\begin{array}{l}\text { Change } \\
\text { in H.R. } \\
\text { (b.p.m.) }\end{array}$ & $\begin{array}{l}\text { Workload } \\
\text { Resistance } \\
\text { Setting } \\
\text { (kilo-ponds) }\end{array}$ & $\begin{array}{l}\text { Age } \\
\text { (yrs.) }\end{array}$ & $\begin{array}{l}\text { Initial } \\
\text { Weight } \\
\text { (pounds) }\end{array}$ \\
\hline A. A. & & 128 & $12 I$ & -7 & 2.5 & 20 & 179 \\
\hline B. C. & & 172 & 165 & -7 & 3.0 & 30 & 164 \\
\hline B. H. & & 160 & 148 & -12 & 3.0 & 21 & 196 \\
\hline J. J. & & 150 & 154 & +4 & 2.0 & 22 & 3.50 \\
\hline E. 0 & & 130 & 130 & 0 & 2.5 & 19 & 162 \\
\hline S. P. & & 156 & 148 & -8 & 3.0 & 27 & 202 \\
\hline D. '. & . & 171 & 168 & -3 & 2.0 & 23 & 137 \\
\hline
\end{tabular}


JOGGING GROUP CHARACTERISTICS

\begin{tabular}{|c|c|c|c|c|c|c|c|c|c|}
\hline $\begin{array}{l}\text { Subject } \\
\text { (Init.) }\end{array}$ & $\begin{array}{l}\text { Init. } \\
\text { H.R. } \\
\text { (b.p.m.) }\end{array}$ & $\begin{array}{l}\text { Final } \\
\text { H.R. } \\
(\mathrm{b} \cdot \mathrm{p} \cdot \mathrm{m} .)\end{array}$ & $\begin{array}{l}\text { Change } \\
\text { in } \\
\text { H.R. } \\
\text { (b.p.m.) }\end{array}$ & $\begin{array}{l}\text { W.I. } \\
\text { Resist. } \\
\text { Setting } \\
(k \cdot p .)\end{array}$ & $\begin{array}{l}\text { Age } \\
\text { (yrs.) }\end{array}$ & $\begin{array}{l}\text { Init. } \\
\text { Wt. } \\
\text { (Ibs.) }\end{array}$ & $\begin{array}{l}\text { Mean } \\
\text { Train. } \\
\text { Intens. } \\
\text { (b.p.m.) }\end{array}$ & $\begin{array}{l}\text { Total } \\
\text { Correct } \\
\text { Train. } \\
\text { Sess. } \\
\text { (of 96) }\end{array}$ & $\begin{array}{l}\text { Houx } \\
\text { Class } \\
\text { Met }\end{array}$ \\
\hline R. A. & 150 & 143 & -7 & 2.0 & 21 & 137 & 148.92 & 80 & $8 \mathrm{TTh}$ \\
\hline V. A. & 146 & 132 & -14 & 2.5 & 29 & 189 & 1.51 .56 & 94 & 9 TTh \\
\hline J. B. & 156 & 142 & -14 & 2.5 & 24 & 190 & 153.54 & 89 & $9 \mathrm{MW}$ \\
\hline R. B. & 172 & 145 & -27 & 2.0 & 22 & 165 & 143.94 & 85 & $8 \mathrm{TTh}$ \\
\hline T. B. & 140 & 139 & -1 & 2.5 & 32 & 167 & 149.94 & 94 & $9 \mathrm{MWN}$ \\
\hline L. F. & 162 & 147 & -.15 & 3.0 & 24 & 193 & 151.32 & 90 & $9 \mathrm{TTh}$ \\
\hline B. G. & 167 & 155 & -12 & 3.0 & 23 & 190 & 153.12 & 85 & $9 \mathrm{MN}$ \\
\hline B. $\mathrm{H}$ & 159 & 130 & -29 & 2.5 & 22 & 183 & 151.56 & 95 & $9 \mathrm{TTh}$ \\
\hline B. $K$. & 146 & 129 & -17 & 2.0 & 19 & 147 & 152.58 & 79 & $8 \mathrm{TTh}$ \\
\hline N. M. & 157 & 135 & -22 & 2.5 & 24 & 143 & 153.84 & 89 & $9 \mathrm{MTN}$ \\
\hline G. M. & 143 & 146 & +3 & 2.5 & 17 & 153 & $151 . .38$ & 88 & $8 \mathrm{TTh}$ \\
\hline G. $O$. & 172 & 157 & -15 & 2.0 & 21 & 171 & 154.08 & 91 & 9 TTh \\
\hline P. P. & 143 & 132 & -11 & 3.0 & 21 & 174 & 150.84 & 93 & $8 \mathrm{THh}$ \\
\hline E. P. & 147 & 134 & -13 & 2.5 & 19 & 149 & 148.26 & 91 & 9 TrTh \\
\hline I. S. & 152 & 152 & 0 & 2.5 & 18 & 148 & 147.06 & 92 & $9 \mathrm{MW}$ \\
\hline I. S. & 1.40 & 106 & -34 & 2.5 & 25 & 200 & 151.14 & 89 & $9 \mathrm{Trh}$ \\
\hline R. S. & 159 & 127 & -32 & 2.0 & 21 & 142 & 149.82 & 91 & $9 \mathrm{Trh}$ \\
\hline J. S. & 159 & 133 & -26 & 2.5 & 29 & 177 & 151.14 & 85 & 9 Trih \\
\hline E. S. & 136 & 108 & -28 & 1.5 & 18 & 142 & 149.28 & 93 & $8 \mathrm{TTh}$ \\
\hline D. T. & 135 & 126 & -9 & 2.5 & 21 & 206 & 151.14 & 95 & $9 \mathrm{MN}$ \\
\hline A. T. & 136 & 145 & +9 & 3.0 & 22 & 180 & 155.76 & 86 & $8 \mathrm{TTh}$ \\
\hline R. V. & 156 & 155 & -1 & 2.5 & 19 & 201 & 153.12 & 91 & 9 Mrn \\
\hline E. W. & 156 & 126 & -30 & 2.0 & 28 & 182 & 154.26 & 83 & $9 \mathrm{~mW}$ \\
\hline
\end{tabular}


F

RUNNING GROUP CHARACTERISTICS

\begin{tabular}{|c|c|c|c|c|c|c|c|c|c|}
\hline $\begin{array}{l}\text { Subject } \\
\text { (Init.) }\end{array}$ & $\begin{array}{l}\text { Init. } \\
\text { H.R. } \\
(\mathrm{b} \cdot \mathrm{p} \cdot \mathrm{m} .)\end{array}$ & $\begin{array}{l}\text { Final } \\
\text { H.R. } \\
(\mathrm{b} \cdot \mathrm{p} \cdot \mathrm{m} .)\end{array}$ & $\begin{array}{l}\text { Change } \\
\text { in } \\
\text { H.R. } \\
\left(b \cdot p \cdot m_{.}\right)\end{array}$ & $\begin{array}{l}\text { W.I. } \\
\text { Resist. } \\
\text { Setting } \\
(k \cdot p \cdot)\end{array}$ & $\begin{array}{l}\text { Age } \\
\text { (yrs.) }\end{array}$ & $\begin{array}{l}\text { Init. } \\
\text { Wt. } \\
\text { (Ibs.) }\end{array}$ & $\begin{array}{l}\text { Mean } \\
\text { Train } \\
\text { Intens. } \\
\text { (b.p.m.) }\end{array}$ & $\begin{array}{l}\text { Total } \\
\text { Correct } \\
\text { Train. } \\
\text { Sess. } \\
\text { (of 96) }\end{array}$ & $\begin{array}{l}\text { Hour } \\
\text { Class } \\
\text { Met }\end{array}$ \\
\hline S. A. & 143 & 141 & -2 & 3.0 & 22 & 200 & 180.78 & 88 & $9 \mathrm{MW}$ \\
\hline V. A. & 147 & 146 & -1 & 3.0 & 19 & 183 & 183.00 & 84 & $9 \mathrm{TTh}$ \\
\hline D. B. & 172 & 141 & -31 & 2.5 & 19 & 158 & 184.26 & 83 & $9 \mathrm{MW}$ \\
\hline G. C. & 157 & 154 & -3 & 2.0 & 21 & 178 & 184.44 & 90 & $9 \mathrm{mrh}$ \\
\hline G. E. & 168 & 153 & -15 & 2.0 & 21 & 143 & 186.06 & 94 & $8 \mathrm{TTh}$ \\
\hline B. F. & 146 & 128 & -18 & 2.5 & 20 & 181 & .183 .72 & 92 & 8 J.Th \\
\hline T. F. & 164 & 160 & -4 & 2.5 & $2 i$ & 172 & 1.86 .06 & 86 & $9 \mathrm{MN}$ \\
\hline T. G. & 169 & 159 & -10 & 3.0 & 21 & 174 & 181.02 & 96 & 9 ITn \\
\hline C. M. & 134 & 134 & 0 & 2.0 & 25 & 144 & 182.16 & 78 & $9 \mathrm{~N}^{\top} \mathrm{N}^{\top}$ \\
\hline D. 0. & 162 & 1.31 & -31 & 2.0 & 20 & 161 & $18 A .50$ & 91 & 9 pro \\
\hline$J . R$. & 154 & 146 & -8 & 3.0 & 28 & 185 & 179.76 & 93. & 9. IrTh \\
\hline C. R. & 168 & 150 & -18 & 2.0 & 18 & 142 & 189.06 & 85 & $\varepsilon \mathrm{MTh}$ \\
\hline R. S. & 153 & 136 & -17 & 2.0 & 17 & 1.17 & 185.58 & 95 & $8 \mathrm{TTh}$ \\
\hline D. S. & 145 & 137 & -8 & 2.5 & 26 & 1.89 & 182.76 & 93 & 9 TTin \\
\hline D. S, & 154 & 140 & -14 & 2,0 & 21 & 141 & 183.72 & 89 & $9 \mathrm{WW}$ \\
\hline H. W. & 174 & 160 & -14 & 2.5 & 22 & 169 & 180.30 & 79 & $8 \mathrm{MTh}$ \\
\hline
\end{tabular}

